\title{
Primary Spinal Chondrosarcoma Localized in the Cervical Spinal Canal and Intervertebral Foramen
}

\author{
- Case Report-
}

\author{
Shiro OHUE, Saburo SAKAKI*, Kanehisa KOHNO*, Kou NAKAgAWA*, \\ Katsusuke KusunOKI, Hirooki TODO*, and Kazuhiko SADAMOTO \\ Department of Neurosurgery, Washokai Sadamoto Hospital, Matsuyama; ${ }^{*}$ Department of \\ Neurosurgery, Ehime University School of Medicine, Ehime
}

\begin{abstract}
A 48-year-old male presented with a very rare case of spinal chondrosarcoma localized in the cervical spinal canal and intervertebral foramen, but without marked destruction of the vertebral column. Spinal chondrosarcoma is characterized by radiological evidence of destruction of the surrounding bone structure and mottled calcification. Magnetic resonance imaging was useful in the diagnosis and determination of the extent of this spinal chondrosarcoma. However, preoperative differential diagnosis of the tumor was not possible based on neuroimaging evidence.
\end{abstract}

Key words: chondrosarcoma, magnetic resonance imaging, cervical spine, spinal canal

\section{Introduction}

Chondrosarcoma constitutes $7 \%$ to $22 \%$ of all primary malignant bone tumors, ${ }^{1,16)}$ although only 11 chondrosarcomas were encountered in a large series of 150 malignant or epidural spinal tumors. ${ }^{19}$ ) The vertebral column is involved in $6 \%$ to $10 \%$ of chondrosarcoma. ${ }^{4,9,17,18)}$ Chondrosarcoma is characterized by radiographic evidence of a large area of bone destruction with irregularly mottled calcification. ${ }^{5,8,10-13)}$

Here we describe an unusual spinal chondrosarcoma localized in the cervical spinal canal and intervertebral foramen and accompanied by little destruction of the corpus or lamina of the vertebrae.

\section{Case Report}

A 48-year-old male presented with progressive numbness of the left hand and foot on June 10, 1989. The numbness of his left hand had begun 6 months before, and numbness subsequently developed in his left foot. On admission, the deep tendon reflexes on the left side were hyperactive, and Babinski sign was absent. Paresthesia of the left fingers and toes was

Received March 7; 1994; Accepted May 19, 1994 found, but not weakness and atrophy of the muscles.

A plain $x$-ray film of the cervical spine revealed enlargement of the left C5-6 intervertebral foramen, but no definite signs of a destructive lesion (Fig. 1).

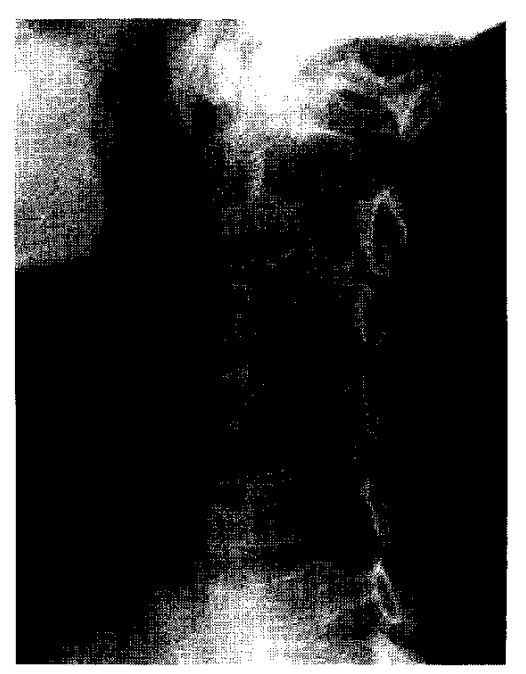

Fig. 1 Left oblique plain $\mathrm{x}$-ray film of the cervical spine showing enlargement of the left C5-6 intervertebral foramen. There is no evidence of destruction of the spine or calcification. 

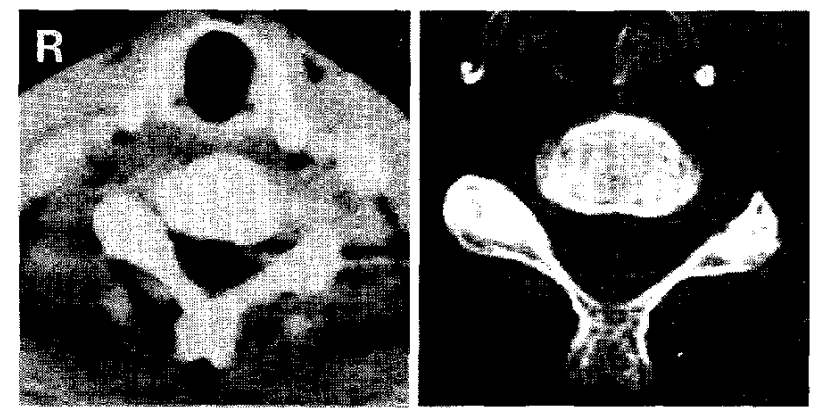

Fig. 2 CT scans at the C5-6 level. left: Postcontrast CT scan demonstrating an enhanced lesion localized in the left ventral part of the spinal canal. Enlargement of the intervertebral foramen is present, but no definite signs of destruction of the vertebrae or associated calcification. right: Myelo-CT scan revealing an extradural mass compressing the spinal cord to the right; posteriorly, the subarachnoid space is visible between the spinal cord and the tumor.

Postcontrast computed tomography (CT) demonstrated an enhanced mass lesion in the left ventral part of the spinal canal at the C5-6 level, enlargement of the C5-6 vertebral foramen, but no destruction of the surrounding bone or calcification (Fig. 2 left). Magnetic resonance (MR) imaging disclosed a mass which was isointense on $\mathrm{T}_{1}$-weighted images and hyperintense on $T_{2}$-weighted images, and enhanced irregularly with gadolinium-diethylenetriaminepenta-acetic acid (Gd-DTPA) (Fig. 3). MR imaging clearly demonstrated that the tumor occupied the ventral part of the spinal canal from $C$ 5 to $C-6$, and extended into the left C5-6 intervertebral foramen. The spinal cord was compressed by the tumor on the left at C5-6. These findings were compatible with a dumbbell type of spinal neurinoma except for the contralateral extension of the tumor. Myelography revealed findings consistent with an extra-axial mass. Myelo-CT revealed that the spinal cord was compressed by the tumor, and the subarachnoid space was narrowed between the tumor and the spinal cord (Fig. 2 right). Vertebral angiography revealed no abnormal findings.

Laminectomies from $\mathrm{C}-4$ to $\mathrm{C}-7$ were performed through a median skin incision with the patient in a prone position on July 20, 1989. The dura mater was spread and flattened at the C5-6 level. Dural incision exposed the spinal cord which was severely compressed by the epidural mass in the left ventral part of the spinal canal. A white, hard elastic, non-vascular mass was found between the dura mater and
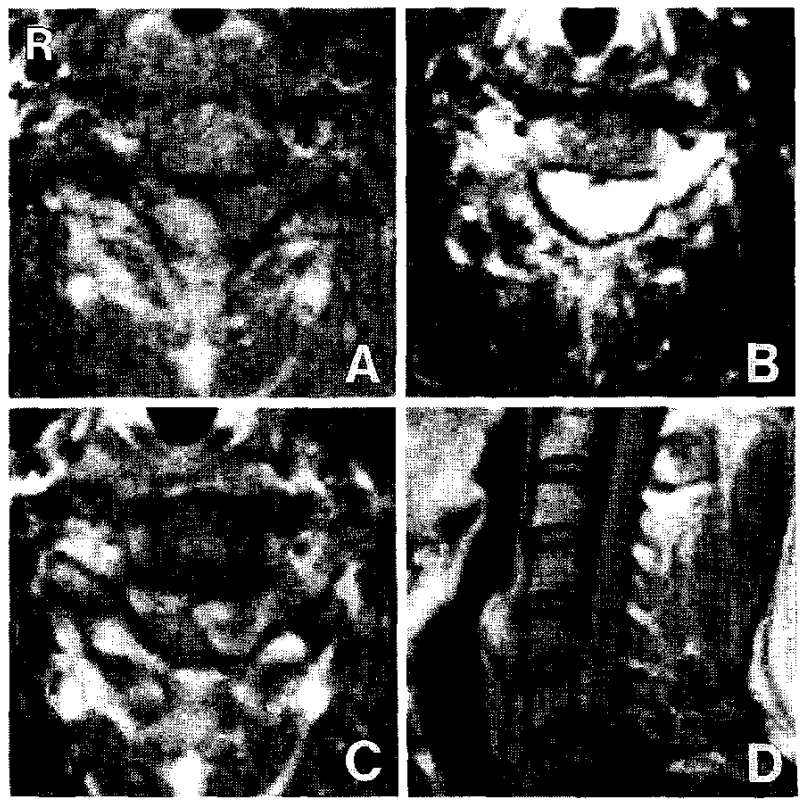

Fig. 3 MR images at the C5-6 level. A: $T_{1}$-weighted axial image with a repetition time (TR) of 500 msec and an echo time (TE) of $25 \mathrm{msec}$ showing an isointense mass in the vertebral part of the spinal canal and the intervertebral foramen. The spinal cord is markedly compressed by the tumor. $\mathbf{B}$ : $\mathbf{T}_{2}$-weighted axial image with TR of $2000 \mathrm{msec}$ and TE of $80 \mathrm{msec}$ showing a hyperintense tumor. $C: T_{1}$-weighted axial image with Gd-DTPA showing irregular enhancement. $\quad D: T_{1}$-weighted sagittal image with Gd-DTPA demonstrating the tumor extending to the ventral side of the spinal cord.

the posterior longitudinal ligament, but did not invade the vertebral column. The origin of the tumor was thought to be the posterior longitudinal ligament. The tumor was totally removed grossly with ultrasonic aspiration, resulting in decompression of the spinal cord. The histological diagnosis of the operative specimens was chondrosarcoma grade I (Fig. 4).

Postoperative MR imaging revealed no residual tumor. No radiotherapy was given and he was discharged without neurological deficits. He returned to his previous work, and was in good health 3 years after the operation.

\section{Discussion}

Plain x-ray films and CT scans demonstrated only the enlargement of the intervertebral foramen without definite evidence of destruction of the bodies 


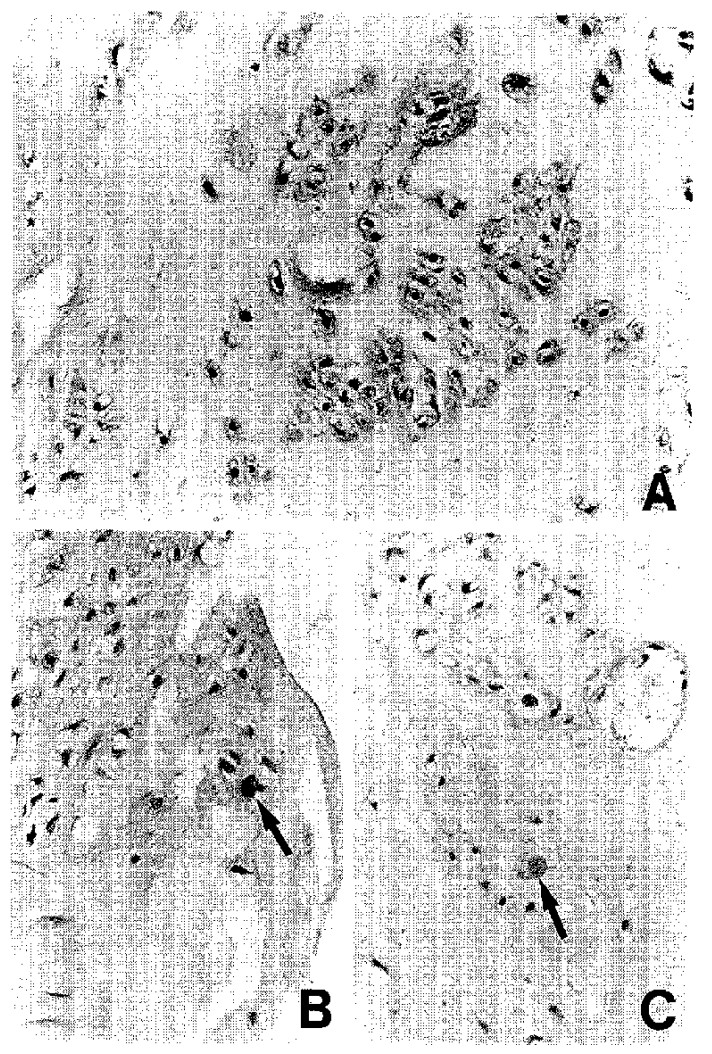

Fig. 4 Photomicrographs of the chondrosarcoma showing a moderate increase in the number of cartilage cells (A). Most cells are well differentiated and show pyknotic nuclei, with occasional binucleate cells (B, arrow), and cells with enlarged nuclei (C, arrow). No mitotic figures are observed. HE stain, A: $\times 200$; B and $C: \times 400$.

and laminae of the cervical vertebrae, and no cauliflower-like or mottled calcification. Chondrosarcoma without definitive destruction of the spinal column and associated calcification has never been reported. This chondrosarcoma was very difficult to differentiate from other extradural tumors, especially spinal neurinoma. A preoperative diagnosis of spinal chondrosarcoma could not have been made based on the available evidence.

The MR imaging appearance of spinal chondrosarcoma is not well documented. MR imaging of chondrosarcoma in other locations shows hypo- or iso-intensity signals on $T_{1}$-weighted images and hyper-intensity signals on $\mathrm{T}_{2}$-weighted images. ${ }^{3)}$ The MR imaging appearance of spinal chondrosarcoma is the same as for chondrosarcoma in other locations. ${ }^{15,20\}}$ In our case, the tumor was isointense on $T_{1}$-weighted images and hyperintense on $\mathrm{T}_{2}$-weighted images. Ad- ministration of Gd-DTPA caused irregular but marked enhancement. MR imaging clearly revealed extension of the spinal tumor, but did not reveal evidence of bone destruction.

Radical excision is the treatment of choice for spinal chondrosarcoma. ${ }^{1,2,6,11}$ However, complete removal of the tumor is not always possible, because the possibility of injury to vital structures. Hirsh et $a l^{11)}$ suggested that surgical extirpation of the spinal tumor, even if partial, is beneficial and prolongs life. Radiotherapy has been used occasionally after incomplete removal. The usefulness of chemotherapy is uncertain.

The prognosis is related to the histological grade of the tumor, ${ }^{7,14}$ which is classified as low, average, or high. Patients with low-grade chondrosarcoma, such as our patient, have a 5-year survival rate after treatment ranging from $71 \%$ to $83 \%$, and the risk of metastasis is low. ${ }^{2,7,17,18)}$ Our patient with chondrosarcoma grade I has resumed his usual activities and was well 3 years after treatment.

\section{References}

1) Aprin H, Riseborough EJ, Hall JE: Chondrosarcoma in children and adolescents. Clin Orthop 166: 226-232, 1982

2) Blaylock RL, Kempe LG: Chondrosarcoma of the cervical spine. Case report. $J$ Neurosurg 44: 500-503, 1976

3) Bloem JL, Bluemm RG, Taminiau AHM, Oosterom AT, Stolk J, Doornbos J: Magnetic resonance imaging of primary malignant bone tumors, Radiographics 7: 425-445, 1987

4) Camins MB, Duncan AW, Smith J, Marcove RC: Chondrosarcoma of the spine. Spine 3: 202-209, 1987

5) Dahlin DC, Henderson ED: Chondrosarcoma, a surgical and pathological problem. Review of 212 cases. J Bone Joint Surg [Amer] 38A: 1025-1038, 1956

6) Eriksson AI, Schiller A, Mankin HJ: The management of chondrosarcoma of bone. Clin Orthop 153: 44-66, 1980

7) Evans HL, Ayala AG, Romsdahl MM: Prognostic factors in chondrosarcoma of bone. Cancer 40: 818 831,1977

8) Gursel B, Yalciner G: Chondrosarcoma of the cervical vertebra: A case report. Arch Otorhinolaryngol 244: 74-76, 1987

9) Henderson ED, Dahlin DC: Chondrosarcoma of bone: A study of two hundred and eighty-eight cases. $J$ Bone Joint Surg [Amer] 45A: 1450-1458, 1963

10) Hermann G, Sacher M, Lanzieri CF, Anderson PJ, Rabinowitz JG: Chondrosarcoma of the spine: An unusual radiographic presentation. Skeletal Radiol 14: $178-183,1985$ 
11) Hirsh LF, Thanki A, Spector HB: Primary spinal chondrosarcoma with eighteen-year follow-up: Case report and literature review. Neurosurgery 14: 747 749,1984

12) Lindbom A, Soderberg G, Spjut HJ: Primary chondrosarcoma of bone. Acta Radiol 55: 81-96, 1961

13) Mayes GB, Wallace $S$, Bernardino ME: Computed tomography of chondrosarcoma. $J$ Comput Assist Tomogr 5: 345-348, 1981

14) Meachim G: Histological grading of chondrosarcomata. J Bone Joint Surg [Br] 61B: 393-394, 1979 (Editorial)

15) Pettersson $H$, Hudson $T$, Hamlin D, Scott $K$, Springfield D, Enneking W, Spanier S: Magnetic resonance imaging of sacrococcygeal tumors. Acta Radiol [Diagn] (Stockh) 26: 161-165, 1985

16) Phemister DB: Cancer of the bone and joint. JAMA 136: 545-554, 1948

17) Pritchard DJ, Lunke RJ, Taylor WF, Dahlin DC,
Medley BE: Chondrosarcoma: A clinicopathologic and statistical analysis. Cancer 45: 149-157, 1980

18) Sanerkin NG, Gallagher P: A review of the behaviour of chondrosarcoma of bone. $J$ Bone Joint Surg [Br] 61B: 395-400, 1979

19) Torma $T$ : Malignant tumors of the spine and the spinal extra-dural space. A study based on 250 histologically verified cases. Acta Chir Scand (Suppl) 225: 1-176, 1957

20) Zanella FE, Friedmann G: Spinal tumors, in Huk WJ, Gademann G, Friedmann G (eds): MRI of Central Nervous System Disease. Berlin, SpringerVerlag, 1990, pp 407-413

Address reprint requests to: S. Ohue, M.D., Department of Neurosurgery, Washokai Sadamoto Hospital, 13-3 Takewara-cho, Matsuyama 790, Japan. 